\title{
Efficacy of two trabecular micro-bypass stents combined with topical travoprost in open-angle glaucoma not controlled on two preoperative medications: 3-year follow-up
}

\author{
This article was published in the following Dove Press journal: \\ Clinical Ophthalmology \\ 15 March 2017 \\ Number of times this article has been viewed
}

\author{
David F Chang' \\ Eric D Donnenfeld ${ }^{2}$ \\ $\mathrm{L}$ Jay Katz ${ }^{3}$ \\ Lilit Voskanyan ${ }^{4}$ \\ Iqbal Ike K Ahmed ${ }^{5}$ \\ Thomas W Samuelson ${ }^{6}$ \\ Jane Ellen Giamporcaro ${ }^{7}$ \\ Dana M Hornbeak ${ }^{7}$ \\ Kerry D Solomon ${ }^{8}$ \\ 'Altos Eye Physicians, Los Altos, \\ CA, ${ }^{2}$ Ophthalmic Consultants of \\ Long Island, Rockville Centre, NY, \\ ${ }^{3}$ Department of Ophthalmology, \\ Wills Eye Hospital, Jefferson Medical \\ College, Philadelphia, PA, USA; \\ ${ }^{4}$ S.V. Malayan Ophthalmology Centre, \\ Yerevan, Armenia; ${ }^{5}$ Department of \\ Ophthalmology and Vision Sciences, \\ University of Toronto, Toronto, ON, \\ Canada; ${ }^{6}$ Minnesota Eye Consultants, \\ Minneapolis, MN, ${ }^{7}$ Glaukos \\ Corporation, San Clemente, CA, \\ ${ }^{8}$ Carolina Eyecare Physicians, Mount \\ Pleasant, SC, USA
}

Purpose: To evaluate the long-term intraocular pressure (IOP)-lowering effect and safety parameters following treatment with two trabecular micro-bypass stents and topical prostaglandin in phakic eyes with open-angle glaucoma (OAG) not controlled on two preoperative medications.

Methods: This prospective, single-arm, unmasked study enrolled 39 qualified phakic eyes with OAG not controlled on 2 medications, preoperative medicated IOP of $18-30 \mathrm{mmHg}$, and IOP following medication washout of $22-38 \mathrm{mmHg}$. Two trabecular micro-bypass stents were implanted as a standalone procedure, and travoprost was started on postoperative day 1. Evaluations included IOP, best-corrected visual acuity, medication use, fundus and slit-lamp examinations, visual field, cup:disc ratio, central corneal thickness, and ocular complications. Data through 18 months were summarized previously. Thirty-seven of the original 39 subjects have been followed for 3 years postoperatively; follow-up is continuing for 5 years.

Results: At 3 years postoperative, $97 \%$ of eyes had achieved an IOP reduction of $\geq 20 \%$ from baseline with a reduction of 1 medication. Eighty-six percent of eyes had IOP of $\leq 18 \mathrm{mmHg}$ with a reduction of 1 medication. Mean medicated IOP decreased to $14.0 \pm 2.6 \mathrm{mmHg}$ on 1 medication versus $22.4 \pm 2.3 \mathrm{mmHg}$ on 2 medications preoperatively. The mean unmedicated IOP decreased to $17.7 \pm 1.7 \mathrm{mmHg}$ at 37 months from $25.3 \pm 1.9 \mathrm{mmHg}$ preoperatively. Longterm postoperative adverse events included cataract surgery in 3 eyes due to cataract progression, and trabeculectomy in 1 eye due to uncontrolled IOP of $23 \mathrm{mmHg}$. No intraoperative or device-related adverse events occurred.

Conclusion: Significant and sustained reduction in IOP and medications with a favorable safety profile was shown through 3 years after implantation of 2 trabecular micro-bypass stents combined with postoperative travoprost in phakic OAG eyes uncontrolled on 2 preoperative medications. These findings demonstrate the long-term performance and safety of trabecular bypass stents in combination with topical prostaglandin for OAG patients.

Keywords: glaucoma, trabecular micro-bypass, MIGS, IOP, medication

\section{Introduction}

The development of microinvasive glaucoma surgery (MIGS) devices and procedures has been one of the most important advances in glaucoma surgery during the past two decades. Substantial data with up to 5 years of follow-up have shown that the implantation of a single trabecular micro-bypass stent (iStent ${ }^{\circledR}$ Trabecular Micro-Bypass; Glaukos Corporation, San Clemente, CA, USA) during cataract
Correspondence: David F Chang Altos Eye Physicians, 762 Altos Oaks Drive, Los Altos, CA 94024, USA

Tel +l 6509489123

Fax + I 6509480563

Email dceye@earthlink.net
Clinical Ophthalmology 2017:II 523-528

(c) (1) (2) ๑ 2017 Chang et al. This work is published and licensed by Dove Medical Press Limited. The full terms of this license are avalable at https:/www.dovepress.com/terms.php cc) hereby accept the Terms. Non-commercial uses of the work are permitted without any further permission from Dove Medical Press Limited, provided the work is properly attributed. For permision for commercial use of this work, please see paragraphs 4.2 and 5 of our Terms (https://www.dovepress. con/terms.php). 
surgery can safely decrease intraocular pressure (IOP) and medications in patients with mild to moderate open-angle glaucoma (OAG) and cataract. ${ }^{1-4}$ Implantation of multiple iStent devices during cataract surgery also has shown benefit in patients with OAG not controlled on medical therapy. ${ }^{5}$ Furthermore, this stent technology has been associated with fewer complications than those reported with incisional glaucoma surgeries. ${ }^{6}$

The goal of the MIGS Study Group was to evaluate the IOP- and medication-lowering effect of trabecular microbypass stent implantation over time in patients with a wide range of OAG severities. A previous study by this Group demonstrated the IOP- and medication-reducing effect of implanting 2 stents in subjects with milder stages of glaucoma. ${ }^{7}$ In the present study, we evaluated standalone implantation of 2 stents combined with topical prostaglandin in subjects with more advanced glaucoma severity. In a previous report for this study, standalone implantation of 2 trabecular micro-bypass stents combined with postoperative travoprost safely reduced IOP and medication usage through 18 months in eyes with OAG uncontrolled on 2 ocular hypotensive medications. ${ }^{8}$ These data supported the hypothetical synergy of increasing conventional aqueous outflow via trabecular micro-bypass stenting and uveoscleral outflow via a prostaglandin analog. This current report summarizes findings through 3 years postoperatively in this series of 39 eyes. Follow-up is ongoing through 5 years.

\section{Methods}

This prospective, single-arm, unmasked study was designed to enroll phakic or pseudophakic subjects with OAG not controlled on 2 preoperative medications. This was defined as medicated IOP of $18-30 \mathrm{mmHg}$ and unmedicated IOP of 22-38 mmHg following medication washout. Patients were required to have a cup:disc $(\mathrm{C}: \mathrm{D})$ ratio of $\leq 0.9$, best-corrected visual acuity (BCVA) of 20/100 or better, and normal angle anatomy. The study excluded subjects with uveitic, traumatic, neovascular, or angle-closure glaucoma; glaucoma associated with vascular disorders; and eyes with prior glaucoma surgery (including argon laser trabeculoplasty, or selective laser trabeculoplasty [SLT] within 90 days prior to screening). Patients could be included if they had a history of any type of laser iridotomy, or if they had SLT $>90$ days prior to screening.

Efficacy and safety criteria included IOP (Goldmann applanation tonometry), BCVA (Early Treatment Diabetic Retinopathy Study criteria), slit lamp biomicroscopy, indirect ophthalmoscopy, C:D ratio, visual field (Swedish Interactive Threshold Algorithm standard 24-2 automated perimetry), pachymetry, medication use, and ocular complications. Postoperatively, patients were evaluated at day 1 ; week 1 ; months $1,3,6$, and 12; and planned for every 6 months thereafter until month 60; outcomes through 3 years are summarized in this report. After measuring the IOP at each annual visit, all medications were stopped for 1 month. The patient then returned 1 month later for a "washout" IOP measurement off medication, prior to resuming the travoprost. Additional ocular hypotensive medication was to be started if postoperative IOP on travoprost exceeded $21 \mathrm{mmHg}$ at any postoperative visit, and/or in the case of concerning visual field or optic nerve findings, as determined by the investigator.

The study was conducted at the S.V. Malayan Ophthalmological Center in Yerevan, Armenia. Surgeries were performed by visiting surgeons from the MIGS Study Group, which includes surgeons and staff from 7 countries. In this specific study, surgeries were performed by the local surgeon (LV) and 5 visiting surgeons from Canada and the United States (IKA, TWS, DFC, EDD, and KDS). Pre- and postoperative examinations were completed by glaucomatrained ophthalmologists at the eye hospital. All subjects signed an informed consent. The study was conducted per the principles governing clinical research as set in the Declaration of Helsinki (2008) and applicable International Organization for Standardization/good clinical practice guidelines. Ethical approval was obtained from the Armenian Ministry of Health. The registration number for this study is NCT01252888 (www.ClinicalTrials.gov).

Previous publications have described the iStent device and implantation technique. ${ }^{1,8-10}$ The titanium iStent is a single-piece, heparin-coated, L-shaped device measuring $1.0 \mathrm{~mm}$ in length, $0.33 \mathrm{~mm}$ in height, and possessing a snorkel bore diameter of $120 \mu \mathrm{m}$. The stent is implanted using a disposable stainless steel inserter, so that the stent body rests within Schlemm's canal and the snorkel projects into the anterior chamber. The stent is designed to create an aqueous bypass channel through the trabecular meshwork directly into Schlemm's canal in order to increase aqueous outflow. Using the previously described implantation methods, 2 iStents were implanted $\sim 2$ hours apart and facing opposite directions in the nasal trabecular meshwork quadrant in each study eye. Following surgery, patients received topical antiinflammatory medication for 4 weeks and topical antibiotic for 1 week. Topical travoprost was started on the evening of postoperative day 1 and continued throughout the follow-up period except for medication washout evaluations.

Proportional analyses of eyes with IOP reduction of $\geq 20 \%$ with reduction of 1 medication versus baseline 
unmedicated IOP were performed at 12, 24, and 36 months. The secondary efficacy endpoint was the proportion of patients with $\mathrm{IOP} \leq 18 \mathrm{mmHg}$ with reduction of 1 medication at 12 months, and this same proportional analysis was conducted at months 24 and 36. Analyses of safety included slit lamp and fundus examinations, and recording adverse events and BCVA. For continuous variables such as mean IOP, mean and standard deviation were calculated on available eyes that had not undergone secondary surgical procedures that could affect IOP.

\section{Results}

\section{Subject accountability}

Of the 39 qualified subjects who underwent ab interno implantation of 2 iStent devices with postoperative administration of topical travoprost, 37 subjects have been followed for 3 years. One of the original 39 subjects died before the 24-month examination and 1 subject was lost to follow-up (left the country) prior to the 36-month examination. Figure 1 shows a flowchart of subject accountability through 3 years of follow-up. Demographic and preoperative parameters were summarized previously in the 18 -month report. ${ }^{8}$

\section{IOP and medication use}

At 3 years postoperative, $97 \%$ of eyes had achieved an IOP reduction of $\geq 20 \%$ with reduction of 1 medication compared to their unmedicated baseline IOP (Figure 2). Compared to their screening preoperative IOP on 2 medications, $88 \%$ of eyes had achieved IOP reduction of $\geq 20 \%$ with reduction of 1 medication. Eighty-six percent of eyes had achieved IOP $\leq 18 \mathrm{mmHg}$ at 3 years with reduction of 1 medication (Figure 3). Figure 4 shows the mean IOP over time through 37 months after stent implantation. At 36 months, mean

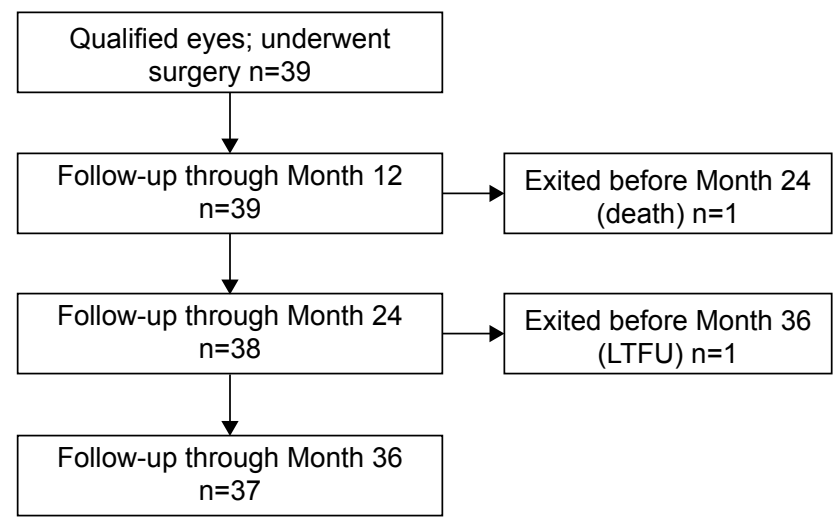

Figure I Subject flowchart through 37-month follow-up period. Abbreviation: LTFU, lost to follow-up.

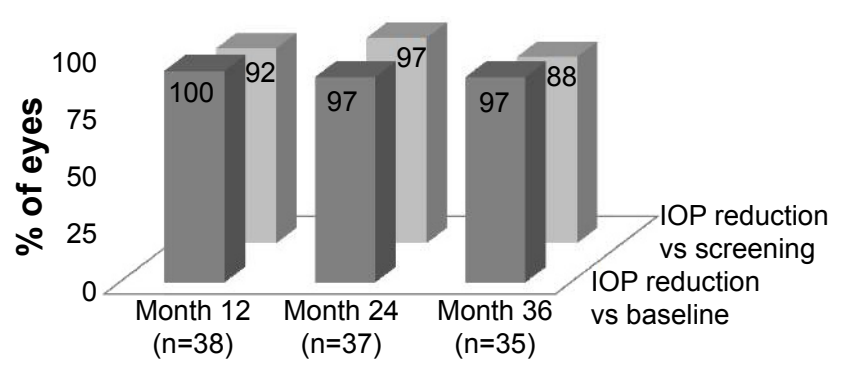

Figure 2 IOP reduction $\geq 20 \%$ versus baseline IOP with reduction of I medication. ${ }^{a}$

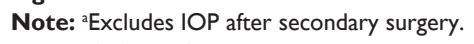

Abbreviation: IOP, intraocular pressure.

medicated IOP had decreased to $14.0 \pm 2.6 \mathrm{mmHg}$ on 1 medication versus $22.4 \pm 2.3 \mathrm{mmHg}$ on 2 medications preoperatively. At 37 months, mean unmedicated IOP (after medication washout) was $17.7 \pm 1.7 \mathrm{mmHg}$ compared to the preoperative washout mean IOP of $25.3 \pm 1.9 \mathrm{mmHg}$.

\section{Additional therapy to manage IOP}

The study protocol mandated that additional ocular hypotensive medication be started if postoperative IOP on travoprost exceeded $21 \mathrm{mmHg}$ at any postoperative visit, or in the case of concerning visual field or optic nerve findings, as determined by the examining ophthalmologist. Three eyes required additional therapy over the 3 -year follow-up period. One subject presented with IOP of $23 \mathrm{mmHg}$ at the 24-month examination and underwent a trabeculectomy shortly thereafter. This subject's IOP at 3 years was $13.7 \mathrm{mmHg}$. Two subjects were prescribed additional medication following the 36-month examination for IOP deemed to be too high by the ophthalmologist for their individual disease $(18 \mathrm{mmHg}$ in the first subject and $20 \mathrm{mmHg}$ in the second subject).

\section{Safety}

All enrolled subjects underwent successful implantation of 2 iStent devices, and no intraoperative adverse events occurred. A total of 13 postoperative adverse events were

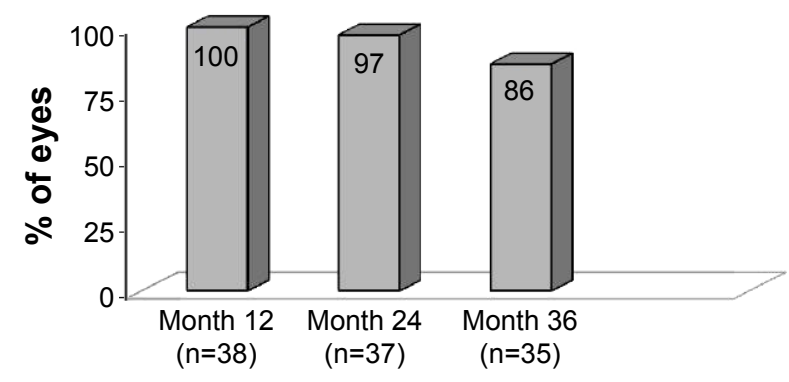

Figure 3 IOP $\leq 18 \mathrm{mmHg}$ with reduction of I medication. ${ }^{\mathrm{a}}$ Note: ${ }^{a}$ Excludes IOP after secondary surgery.

Abbreviation: IOP, intraocular pressure. 


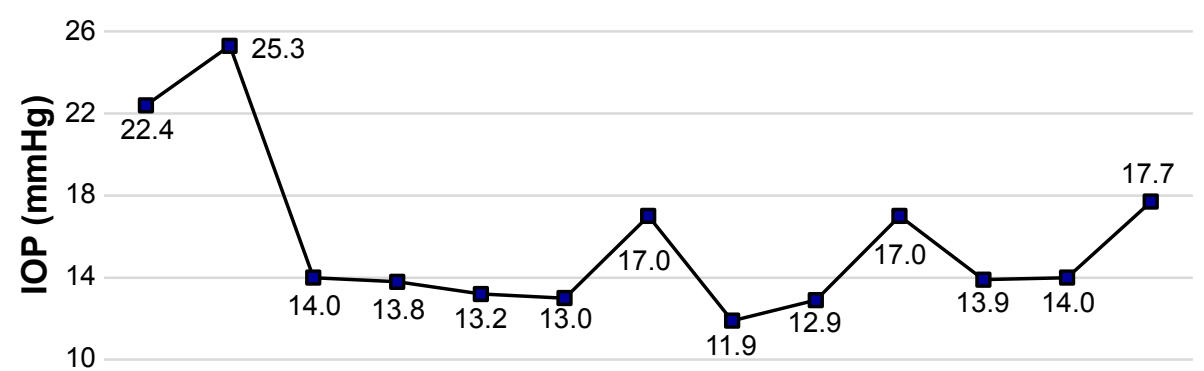

\begin{tabular}{|c|c|c|c|c|c|c|c|c|c|c|c|c|c|}
\hline & Screening & Baseline $^{b}$ & M1 & M3 & M6 & M12 & M13 ${ }^{b}$ & M18 & M24 ${ }^{\mathrm{C}}$ & M25 ${ }^{b}$ & M30 & M36 & M37 ${ }^{d}$ \\
\hline $\mathrm{n}$ & 39 & 39 & 39 & 39 & 38 & 38 & 38 & 38 & 37 & 36 & 34 & 34 & 31 \\
\hline Mean & 22.4 & 25.3 & 14.0 & 13.8 & 13.2 & 13.0 & 17.0 & 11.9 & 12.9 & 17.0 & 13.9 & 14.0 & 17.7 \\
\hline SD & 2.3 & 1.9 & 2.2 & 1.8 & 1.8 & 2.4 & 2.3 & 2.1 & 2.3 & 2.0 & 1.8 & 2.6 & 1.7 \\
\hline
\end{tabular}

Figure 4 Mean IOP over time. ${ }^{a}$

Notes: ${ }^{a}$ Excludes IOP after secondary surgery. ${ }^{b} \mathrm{OOP}$ measured after medication washout. ${ }^{\circ}$ Trabeculectomy for I subject at 24 months. ${ }^{\mathrm{d}}$ Two subjects not included in analysis had second medication added at 36 months.

Abbreviations: IOP, intraocular pressure; SD, standard deviation; M, month.

reported among 10 different subjects. Two subjects had transient hypotony at day 1 which resolved by week $1 ; 1$ of these subjects also had fluctuating BCVA during follow-up and BCVA loss $>1$ line at month 36 due to preexisting visual field loss involving fixation. Five subjects had progression of preexisting cataracts causing at least 1 line of BCVA loss. Four of these 5 patients underwent cataract surgery. One subject had BCVA loss $>1$ line at month 3 due to malaise/insomnia which resolved by the next visit. The subject who required a trabeculectomy (as previously described) had BCVA loss $>1$ line post-trabeculectomy; month 36 BCVA was 20/100. Unrelated to the study procedure, 1 subject developed a herpetic corneal ulcer and subsequent scar which caused BCVA loss $>1$ line (to 20/50) at month 37. No serious or device-related adverse events occurred. The mean C:D ratio, visual field mean deviation, and central corneal thickness remained stable over the 37-month follow-up period (Table 1).

\section{Discussion}

Over the past decade, numerous studies of MIGS with trabecular micro-bypass stents have documented IOP and medication reduction either in conjunction with cataract surgery $^{1-5}$ or as a sole procedure..$^{7-8}$ The earlier report on subjects in this prospective, single-arm, unmasked study found substantial reduction in IOP and medication with a favorable safety profile through 18 months. ${ }^{8}$ The present report confirms that this efficacy is maintained through 36 months postoperatively.

The long-term data through month 36 show sustained IOP and medication reduction in all but 3 subjects that required additional therapy. Mean medicated IOP on 1 medication had decreased by $8.4 \mathrm{mmHg}$ from the preoperative IOP on 2 medications. Ninety-seven percent of eyes had achieved an IOP reduction $\geq 20 \%$ from baseline with reduction of 1 medication, and $86 \%$ of eyes had IOP $\leq 18 \mathrm{mmHg}$ with reduction of 1 medication. This substantial IOP reduction in the majority of study eyes may reflect a sustained synergy between increased conventional outflow via the implanted stents and increased uveoscleral outflow via a prostaglandin medication. The reduction in number of medications is clinically important because patient compliance has been shown to decrease significantly with multiple versus single medications. ${ }^{11}$ The observed 30\% reduction in medication-free IOP achieved at 37 months provides an estimate of the isolated effect of the MIGS procedure alone. In light of the well-documented problems with medication compliance in general, ${ }^{12,13}$ this

Table I Screening and annual postoperative mean C:D ratio, visual field, and central corneal thickness, available eyes at each visit

\begin{tabular}{lllll}
\hline Ocular parameter & Screening, $\mathbf{N}=\mathbf{3 9}$ & Month I 2, N=39 & Month 24, N=38 & Month 36, N=37 \\
\hline C:D ratio, mean (SD) & $0.7(0.1)$ & $0.7(0.1)$ & $0.7(0.1)$ & $0.7(0.1)$ \\
VF-mean deviation (dB), mean (SD) & $-6.4(6.9)$ & $-5.9(7.1)$ & $-5.2(7.1)$ & $-5.2(6.8)$ \\
VF-pattern SD (dB), mean (SD) & $3.0(1.9)$ & $2.1(2.5)$ & $3.1(2.5)$ & $2.5(2.3)$ \\
Corneal thickness $(\mu \mathrm{m})$, mean (SD) & $540.9(40.3)$ & $541.1(41.1)$ & $543.3(40.3)$ & $543.3(40.9)$ \\
\hline
\end{tabular}

Abbreviations: C:D, cup:disc; SD, standard deviation; VF, visual field. 
suggests that even if medication doses are omitted, the independent effect of 2 iStent devices is substantial. Such a method of IOP reduction that is independent of patient compliance would be expected to provide more consistent IOP control over time.

Favorable safety was maintained over the 3 years of follow-up, with no intraoperative or device-related adverse events. Only 1 eye required additional surgical intervention (trabeculectomy) because of glaucoma. There were no postoperative device-specific complications such as inflammation or stent occlusion. Subject accountability was excellent through 3 years, with only 1 subject lost to follow-up.

We acknowledge several shortcomings of this study. The sample size was limited ( $n=39), 100 \%$ of patients were Caucasian, and diurnal IOP was not measured. Clinicians and subjects were not masked to treatment, and there was no control group. Subjects' lens status was not graded in a uniform manner preoperatively, and there were no standardized indications for performing cataract surgery during the postoperative period. Given that this study was performed at a single site, it was not possible to assess site-specific influences on study outcomes. Finally, this report presents postoperative data through 3 years and even longer follow-up is desirable.

Nevertheless, 3-year data from this study provide a valuable measurement of the IOP-and medication-lowering effects of 2 iStent devices implanted as a standalone procedure together with postoperative prostaglandin medication. Because of its Food and Drug Administration indication, most US clinical experience with the iStent has been in conjunction with phacoemulsification. Because cataract surgery alone can lower IOP, the effect of the MIGS procedure is therefore difficult to isolate in these eyes. The pre- and postoperative medication washout assessments in this study provide a direct estimation of the IOP-lowering effect of 2 iStents, independent of medication use, treatment compliance, or cataract extraction. The substantial decrease in IOP, together with the safety profile and reduction in number of medications over at least a 3-year time frame, suggests that standalone implantation of multiple iStents may be a reasonable alternative to prescribing maximal medical therapy in patients with moderate glaucoma.

\section{Acknowledgments}

The sponsor, Glaukos Corporation, San Clemente, CA, USA, provided study devices, sponsorship for performing this study, data collection, data management, data analysis, and editorial assistance in the preparation of this manuscript.

\section{Disclosure}

Drs Donnenfeld, Solomon, Chang, Samuelson, Ahmed, and Katz received nonfinancial support for their work as investigators in this study. Drs Voskanyan, Chang, and Samuelson received financial support from Glaukos for their work as investigators in this study. Dr Katz received financial support from Glaukos for his work as a medical monitor for this study. Drs Donnenfeld, Solomon, Samuelson, Ahmed, and Katz received nonstudy financial support from Glaukos. All authors except Dr Chang are consultants of Glaukos. Jane Ellen Giamporcaro and Dana Hornbeak are employees of Glaukos. The authors report no other conflicts of interest in this work.

\section{References}

1. Samuelson TW, Katz LJ, Wells JM, Duh YJ, Giamporcaro JE; US iStent Study Group. Randomized evaluation of the trabecular micro-bypass stent with phacoemulsification in patients with glaucoma and cataract. Ophthalmology. 2011;118(3):459-467.

2. Fea AM. Phacoemulsification versus phacoemulsification with microbypass stent implantation in primary open-angle glaucoma. J Cataract Refract Surg. 2010;36(3):407-412.

3. Craven ER, Katz LJ, Wells JM, Giamporcaro JE; iStent Study Group. Cataract surgery with trabecular micro-bypass stent implantation in patients with mild-to-moderate open-angle glaucoma and cataract: two-year follow-up. J Cataract Refract Surg. 2012;38(8):1339-1345.

4. Arriola-Villalobos P, Martinez-de-la-Casa JM, Diaz-Valle D, Fernández-Pérez C, García-Sánchez J, García-Feijoó J. Combined iStent trabecular micro-bypass stent implantation and phacoemulsification for coexistent open-angle glaucoma and cataract: a long-term study. $\mathrm{Br} J$ Ophthalmol. 2012;96(5):645-649.

5. Belovay GW, Naqi A, Chan BJ, Rateb M, Ahmed II. Using multiple trabecular micro-bypass stents in cataract patients to treat open-angle glaucoma. J Cataract Refract Surg. 2012;38(11):1911-1917.

6. Rulli E, Biagioli E, Riva I, et al. Efficacy and safety of trabeculectomy vs nonpenetrating surgical procedures: a systematic review and metaanalysis. JAMA Ophthalmol. 2013;131(12):1573-1582.

7. Donnenfeld ED, Solomon KD, Voskanyan L, et al. A prospective 3-year follow-up trial of implantation of two trabecular microbypass stents in open-angle glaucoma. Clin Ophthalmol. 2015;9:2057-2065.

8. Ahmed II, Katz LJ, Chang DF, et al. Prospective evaluation of microinvasive glaucoma surgery with trabecular microbypass stents and prostaglandin in open-angle glaucoma. J Cataract Refract Surg. 2014;40(8):1295-1300.

9. Spiegel D, Garcia-Feijoo J, Garcia-Sanchez J, Lamielle H. Coexistent primary open-angle glaucoma and cataract: preliminary analysis of treatment by cataract surgery and the iStent trabecular micro-bypass stent. Adv Ther. 2008;25(5):453-464.

10. Spiegel D, Wetzel W, Neuhann T, et al. Coexistent primary openangle glaucoma and cataract: interim analysis of a trabecular microbypass stent and concurrent cataract surgery. Eur J Ophthalmol. 2009;19(3):393-399.

11. Robin AL, Novack GD, Covert DW, Crockett RS, Marcic TS. Adherence in glaucoma: objective measurements of once-daily and adjunctive medication use. Am J Ophthalmol. 2007;144(4):533-540.

12. Muir KW, Lee PP. Glaucoma medication adherence; room for improvement in both performance and measurement. Arch Ophthalmol. 2011;129(2):243-245.

13. Schwartz GF, Reardon G, Mozaffari E. Persistency with latanoprost or timolol in primary open angle glaucoma suspects. Am J Ophthalmol. 2004;137(Suppl 1):S13-S16. 


\section{Publish your work in this journal}

Clinical Ophthalmology is an international, peer-reviewed journal covering all subspecialties within ophthalmology. Key topics include: Optometry; Visual science; Pharmacology and drug therapy in eye diseases; Basic Sciences; Primary and Secondary eye care; Patient Safety and Quality of Care Improvements. This journal is indexed on

Submit your manuscript here: http://www.dovepress.com/clinical-ophthalmology-journal
PubMed Central and CAS, and is the official journal of The Society of Clinical Ophthalmology (SCO). The manuscript management system is completely online and includes a very quick and fair peer-review system, which is all easy to use. Visit http://www.dovepress.com/ testimonials.php to read real quotes from published authors. 